\title{
Association of MMP-9 gene polymorphisms with acute coronary syndrome in the Uygur population of China
}

\author{
Lei Wang, Yi-tong Ma, Xiang Xie, Yi-ning Yang, Zhen-yan Fu, Fen Liu, Xiao-mei Li, Bang-dang Chen \\ Department of Cardiology, First Teaching Hospital of Xinjiang Medical University, Urumqi 830011, China
}

Corresponding Author: Yi-tong Ma,Email: myt-xj@163.com

BACKGROUND: Matrix metalloproteinase-9 (MMP-9) plays a pivotal role in early atherosclerosis, vascular remodeling and development of atherosclerotic lesion. The potentially functional MMP-9 gene polymorphism may contribute to the susceptibility of acute coronary syndrome (ACS). This study aimed to investigate the association between two single nucleotide polymorphisms (-1562C>T, R279Q) of the MMP-9 gene in patients with ACS in the Uygur population of China.

METHODS: This case-control study was composed of 361 ACS patients and 432 control subjects, who had undergone coronary angiography. Among the ACS patients, $162(44.9 \%)$ had single-vessel disease, $145(40.2 \%)$ had two-vessel disease, and $54(14.9 \%)$ had three-vessel disease. The genotypes of the two selected SNPs were determined by the method of polymerase chain reaction and restriction fragment length polymorphism (RFLP-PCR). The relationship between the polymorphism of the MMP-9 gene and the severity of coronary arterial stenosis was analyzed.

RESULTS: Analysis of the two SNPs showed that the frequency of CT and TT genotypes in patients with ACS was significantly higher than that in the control group (ACS vs. controls; CT+TT: $25.5 \%$ vs. $15.8 \%, P=0.001)$. And the -1562 gene allele $(\mathrm{C} / \mathrm{T})$ was significantly associated with acute coronary syndrome (ACS vs. controls; C allele: $85.7 \%$ vs. $91.5 \%$, T allele: $14.3 \%$ vs. $8.5 \%, P<0.001$ ). But the frequencies of CT+TT and CC genotypes were not statistically different among ACS patients with one, two and three or more significantly diseased vessels $(P=0.55)$. The R279Q polymorphism site with regard to the association with ACS was not significant $(P>0.05)$. The presence of CT or TT genotypes, assuming codominant effect of the $T$ allele, was independently associated with increased risk of coronary artery disease when adjustment was made for age, body mass index, smoking, hypertension and diabetes mellitus [odds ratio=1.737 (95\% confidence interval, 1.337-2.257), $P=0.018]$.

CONCLUSIONS: MMP-9-1562C>T polymorphism is associated with the susceptibility to ACS in the Uygur population of China. However, this mutation apparently is not related to the severity of coronary arterial stenosis. Another SNP (R279Q) polymorphism of MMP-9 is not significantly associated with the risk of ACS.

KEY WORDS: Matrix metalloproteinase-9; Acute coronary syndrome; Uygur; Gene polymorphism

World J Emerg Med 2011;2(2):104-110

\section{INTRODUCTION}

Acute coronary syndrome (ACS) consists of unstable angina pectoris, non-ST segment elevation myocardial infarction and ST segment elevation myocardial infarction. The pathogenic mechanism of ACS is most often based on thrombosis secondary to plaque rupture in atherosclerosis (AS). ${ }^{[1]}$ In many countries including China, ACS is a main cause of mortality and morbidity. ACS is mainly caused by coronary atherosclerotic plaque rupture or erosion and subsequent 
intracoronary thrombus formation. ${ }^{[2,3]}$ Age, gender, smoking, hypertension, hypercholesterolemia, diabetes mellitus, obesity and sedentary lifestyle are reported to be associated with $\mathrm{ACS},{ }^{[4-6]}$ but the exact mechanism of ACS is still not clear. There is a genetic association between polymorphic variants in candidate genes and atherosclerosis. The matrix metalloproteinase (MMP) family is one of the potential candidate gene systems.

Proteins of the matrix metalloproteinase (MMP) family are involved in the breakdown of the extracellular matrix in normal physiological processes, such as embryonic development, reproduction, and tissue remodeling, as well as in disease processes, such as arthritis and metastasis. ${ }^{[7]}$ Most MMPs are secreted as inactive proproteins which are activated when cleaved by extracellular proteinases. Henney et $\mathrm{al}^{[8]}$ reported that genetic change which affects the expression of MMPs may contribute to the occurrence of cardiovascular disease. Matrix metallopeptidase 9 (MMP-9), also known as $92 \mathrm{kDa}$ type IV collagenase, $92 \mathrm{kDa}$ gelatinase or gelatinase B (GELB), is an enzyme that in humans is encoded by the MMP9 gene. MMP-9 is highly expressed in the vulnerable regions of atherosclerotic plaques. For this reason, MMP-9 plays a key role in vascular remodeling and development of atherosclerotic lesion, and plays a potential role in arterial plaque rupture. ${ }^{[9,10]}$ Epidemiological studies ${ }^{[11,12]}$ showed that MMP-9 levels increased in the circulation of patients with ACS. The potentially functional MMP-9 gene polymorphisms may contribute to the susceptibility of ACS. Two polymorphisms of MMP$9(-1562 \mathrm{C}>\mathrm{T}, \mathrm{R} 279 \mathrm{Q})$ were included in this study. The study aimed to investigate the association between MMP-9 gene polymorphism and ACS in a Uygur population of Xinjiang, China.

\section{METHODS \\ Study population}

The study was designed as a case-control study. A total of 793 Uygur patients were recruited from January 2006 to March 2010 in the First Hospital of Xinjiang Medical University, Urumqi, China. The study group consisted of 361 patients with ACS (106 females and 255 males) confirmed by coronary arteriography, with a mean age of $61.53 \pm 10.47$ years. All the patients were diagnosed according to their medical history, clinical symptoms, 12-lead electrocardiogram, and laboratory examinations, and were confirmed by coronary arteriography ( $\geq 50 \%$ stenosis affected at least one major coronary vessel). Recorded were the data including lipid profile, smoking habit, blood glucose, body mass index, history of hypertension (systolic blood pressure $\geq 140$ $\mathrm{mmHg}$, diastolic blood pressure $\geq 90 \mathrm{mmHg}$, or both), diabetes mellitus and family history of CAD.

Totally 432 patients (170 females and 262 males) served as a control group, with a mean age of $59.56 \pm 9.52$ years. They had normal electrocardiograph, normal blood chemistry values, normal coronary arteriography, no history of heart disease, and no chest pain. All patients were genetically-unrelated ethnic Uygur people from Xinjiang Uygur Autonomous Region. Each patient was interviewed after informed consent was obtained.

The study was approved by the Ethics Committee of the First Hospital Affiliated to Xinjiang Medical University. Neither the patients nor the controls had congenital heart disease, rheumatic heart disease, heart failure, multiple organ failure and other general illnesses.

\section{Coronary angiography}

All patients received routine biplane coronary angiography using the Judkins technique. Coronary angiograms were evaluated by two experienced cardiologists. Coronary artery disease (CAD) was defined as the presence of $\geq 50 \%$ stenosis in at least one major coronary artery. The extent of ACS was defined according to the number of major coronary arteries affected, namely, one-vessel, two-vessel, and three-vessel disease. The number of stenotic coronary vessels was used for assessing the severity of coronary atherosclerosis.

\section{Laboratory examination}

Five milliliter venous blood samples were obtained from all patients at 12 hours after fasting, and were put into EDTA tubes and stored at $-80^{\circ} \mathrm{C}$ for use. The serum concentrations of triglyceride (TG), total cholesterol (TC), low density lipoprotein cholesterol (LDL-C), high density lipoprotein cholesterol (HDL-C), and blood glucose were measured by the standard methods used in the clinical laboratory of the hospital.

\section{MMP-9 genotyping}

Blood samples were collected using a venipuncture technique, and were put into EDTA-containing tubes. DNA was extracted from peripheral vein blood leukocytes using a whole blood genome extraction kit (Boiteke Corporation, Beijing, China). Primers were designed by the Primer Premier 5.0 software (PREMIER Biosoft International, Vancover, Canada). Syntheses were performed by the Shanghai Biological Engineering 
Table 1. PCR primer sets and conditions for the MMP-9 gene

\begin{tabular}{|c|c|c|c|c|c|c|c|}
\hline \multicolumn{2}{|c|}{ Polymorphism (dbSNP No.) Primer sequence (sense/antisense) } & Initial denature & Denature & Annealing & Extension & Cycles & Final incubation \\
\hline$-1562 \mathrm{C}>\mathrm{T}$ & F:5'-GCCTGGCACATAGTAGGCCC-3' & $95^{\circ} \mathrm{C}$ & $94^{\circ} \mathrm{C}$ & $64.5^{\circ} \mathrm{C}$ & $72{ }^{\circ} \mathrm{C}$ & 35 & $72^{\circ} \mathrm{C}$ \\
\hline$(\mathrm{rs} 3918242)$ & R:5'-CTTCCTAGCCAGCCGGCATC-3' & $5 \mathrm{~min}$ & $30 \mathrm{~s}$ & $30 \mathrm{~s}$ & $45 \mathrm{~s}$ & & $10 \mathrm{~min}$ \\
\hline R279Q & F:5'-ATGGGTCAAAGAACAGGA-3' & $95^{\circ} \mathrm{C}$ & $94{ }^{\circ} \mathrm{C}$ & $58^{\circ} \mathrm{C}$ & $72{ }^{\circ} \mathrm{C}$ & 30 & $72{ }^{\circ} \mathrm{C}$ \\
\hline (rs17576) & R:5'-GGTAGACAGGGTGGAGG-3' & $5 \mathrm{~min}$ & $30 \mathrm{~s}$ & $30 \mathrm{~s}$ & $30 \mathrm{~s}$ & & $7 \mathrm{~min}$ \\
\hline
\end{tabular}

PCR: polymerase chain reaction

Table 2. Restriction enzymes, conditions and product lengths for analysis of the MMP-9 gene

\begin{tabular}{llll}
\hline Polymorphism & Restriction enzyme & Conditions & Fragment length (bp) \\
\hline$-1562 \mathrm{C}>\mathrm{T}$ & SphI & $37^{\circ} \mathrm{C}$ for $16 \mathrm{~h}$ : PCR product $8 \mu \mathrm{L}, 10 \times$ buffer $2 \mu \mathrm{L}$, & CC $435 / 435$ \\
$(\mathrm{rs} 3918242)$ & $\mathrm{H}_{2} \mathrm{O}_{2} 10 \mu \mathrm{L}, \mathrm{SphI} 2 \mathrm{U}$ & $\mathrm{CT} 435 / 188,247$ \\
& & & TT 188, 247/188, 247 \\
R279Q & SmaI & $37^{\circ} \mathrm{C}$ for $16 \mathrm{~h}$ : PCR product $8 \mu \mathrm{L}, 10 \times$ buffer $2 \mu \mathrm{L}$, & GG 96, 181/96, 181 \\
$(\mathrm{rs} 17576)$ & $\mathrm{H}_{2} \mathrm{O}_{2} 10 \mu \mathrm{L}$, SmaI 2 U & GA 96, 181bp/277 \\
& & AA 277/277 \\
\hline
\end{tabular}

Table 3. Clinical characteristics of the ACS group and the control group

\begin{tabular}{lccr}
\hline Variables & $\begin{array}{c}\text { ACS group } \\
(n=361)\end{array}$ & $\begin{array}{c}\text { Control group } \\
(n=432)\end{array}$ & $P$ value \\
\hline Age (yeras) & $61.53 \pm 10.47$ & $59.56 \pm 9.52$ & 0.204 \\
TC $(\mathrm{mmol} / \mathrm{L})$ & $4.41 \pm 1.16$ & $4.16 \pm 0.99$ & 0.010 \\
TG $(\mathrm{mmol} / \mathrm{L})$ & $1.97 \pm 1.08$ & $1.94 \pm 0.65$ & 0.753 \\
LDL-C $(\mathrm{mmol} / \mathrm{L})$ & $2.46 \pm 0.84$ & $2.34 \pm 0.75$ & 0.170 \\
HDL-C (mmol/L) & $0.97 \pm 0.25$ & $1.31 \pm 0.67$ & $<0.001$ \\
BMI $\left(\mathrm{kg} / \mathrm{m}^{2}\right)$ & $27.10 \pm 3.59$ & $24.99 \pm 3.17$ & $<0.001$ \\
Smoking (no. \%) & $169(46.8)$ & $140(32.4)$ & $<0.001$ \\
Drinking (no. \%) & $135(37.4)$ & $173(40.0)$ & 0.446 \\
Diabetes mellitus (no. \%) & $75(20.8)$ & $43(10.0)$ & $<0.001$ \\
Hypertension (no. \%) & $171(47.4)$ & $141(32.6)$ & $<0.001$ \\
\hline
\end{tabular}

Company Limited. The reaction was performed in a $25 \mu \mathrm{L}$ final volume and contained $1 \mu \mathrm{L}$ each primer $(10 \mathrm{pmol} / \mu \mathrm{L}), 12.5 \mu \mathrm{L} 2 \times$ Power TaqPCR Master Mix (Boiteke Corporation, Beijing, China) and $1 \mu \mathrm{L}$ genomic DNA. The PCR products of $-1562 \mathrm{C}>\mathrm{T}$ and $\mathrm{R} 279 \mathrm{Q}$ polymorphism sites were digested with the restriction enzyme SphI and SmaI (Fermentas, Lithuania) at 37 ${ }^{\circ} \mathrm{C}$ for 16 hours, separated by electrophoresis on a $2 \%$ agarose gel, and visualized by ethidium bromide.

The MMP-9-1562C allele was not cut; it produced a 436-base pair (bp) fragment, and the MMP-9 -1562T allele was cut into fragments of 194 and $242 \mathrm{bp}$. The MMP-9 279R allele was not cut, but it produced a 277bp fragment, and the MMP-9 279Q allele was cut into fragments of 181 and $96 \mathrm{bp}$. Detailed descriptions of the methods are summarized in Tables 1 and 2.

\section{Statistical analysis}

All data were analyzed using SPSS for Windows 13.0 (SPSS Inc, Chicago, Illinois, USA).The polymorphisms were tested for confirmation with Hardy-Weinberg expectations in the ACS group and control group. Differences in demographic characteristics, selected variables and frequencies of the genotypes, alleles of the two MMP-9 polymorphisms between the two groups were evaluated using the chi-square test (for categorical variables) and Student's $t$ test (for continuous variables). The association between MMP-9 variant genotypes and ACS risk was estimated by odds ratios (ORs) and their 95\% confidence intervals (CIs) using univariate analysis. The factors associated with ACS were evaluated using multifactor logistic regression. A $P$ value less than 0.05 was considered statistically significant.

\section{RESULTS \\ Clinical characteristics}

The comparison of clinical characteristics between the ACS group and the control group is shown in Table 3 . There were no significant differences in age, triglyceride, LDL-cholesterol and drinking between the two groups $(P>0.05)$. However, total cholesterol and body mass index were significantly higher in the ACS group than in the control group $(P=0.01$ and $P<0.001$, respectively), whereas HDL-cholesterol was significantly lower in the ACS group than in the control group $(P<0.001)$. There were significantly higher percentages of smokers and patients with diabetes mellitus, hypertension in the ACS group $(P<0.001)$.

\section{MMP-9-1562C $>$ T and $R 279 Q$ allele frequency and genotype distribution}

Table 4 shows the distribution of genotypes and the prevalence of alleles in the ACS group and the control 
group. The distribution of genotypes was not significantly different from the Hardy-Weinberg equilibrium in both groups $(P>0.05)$. The frequencies of $\mathrm{C} / \mathrm{C}, \mathrm{C} / \mathrm{T}$ and $\mathrm{T} / \mathrm{T}$ of MMP-9 (-1562C $>$ T) polymorphism were $74.5 \%, 22.4 \%$ and $3.1 \%$ in the ACS group, and $84.2 \%, 14.7 \%$ and $1.1 \%$ in the control group $(P=0.002)$. The homozygote TT and the heterozygote $\mathrm{CT}$ were more frequent in the ACS group, and the $-1562 \mathrm{~T}$ allele frequency was significantly higher in the ACS group than in the control group (25.5\% vs. $15.8 \%, P=0.001$ and $14.3 \%$ vs. $8.5 \%, P<0.001$, respectively). There were no significant differences in genotypes and allele distribution of the MMP-9 gene R279Q polymorphism between the two groups $(P>0.05)$. We found that the patients with CT or TT genotype had a higher risk of ACS (vs. CC genotype; CT: $O R=1.73$, $P=0.003$; TT: $O R=3.01, P=0.034$ ). Patients with T allele

Table 4. Genotype distribution and allele frequencies of MMP-9 polymorphism between the two groups

\begin{tabular}{lcclll}
\hline $\begin{array}{l}\text { MMP-9 } \\
\text { polymorphisms }\end{array}$ & ACS group & {$[n=361(\%)]$} & $\begin{array}{c}\text { Control group } \\
{[n=437(\%)]}\end{array}$ & OR $(95 \% \mathrm{CI})$ & $P$ value \\
\hline$-1562 \mathrm{C}>\mathrm{T}$ & & & & \\
CC & $269(74.5)$ & $368(84.2)$ & 1 & \\
$\mathrm{CT}$ & $81(22.4)$ & $64(14.7)$ & $1.73(1.204-2.491)$ & 0.003 \\
TT & $11(3.1)$ & $5(1.1)$ & $3.01(1.034-8.763)$ & 0.034 \\
CT+TT & $92(25.5)$ & $69(15.8)$ & $1.82(1.286-2.587)$ & 0.001 \\
C allele & $619(85.7)$ & $800(91.5)$ & 1 & & \\
T allele & $103(14.3)$ & $74(8.5)$ & $1.80(1.311-2.469)<0.001$ \\
R279Q & & & & \\
RR & $123(34.1)$ & $162(37.1)$ & 1 & \\
RQ & $152(42.1)$ & $191(43.7)$ & $1.05(0.764-1.439)$ & 0.771 \\
QQ & $86(23.8)$ & $84(19.2)$ & $1.35(0.921-1.974)$ & 0.124 \\
RQ+QQ & $238(65.9)$ & $275(62.9)$ & $1.14(0.852-1.526)$ & 0.379 \\
R allele & $398(55.1)$ & $515(58.9)$ & 1 & \\
Q allele & $324(44.9)$ & $359(41.1)$ & $1.17(0.957-1.425)$ & 0.127 \\
\hline
\end{tabular}

Table 5. Number of patients with 1,2 , and 3 stenotic coronary arteries according to MMP-9 genotype (no. \%)

\begin{tabular}{|c|c|c|c|c|}
\hline Genotype & $\begin{array}{l}\text { With } 1 \text { stenotic } \\
\text { vessel }\end{array}$ & $\begin{array}{l}\text { With } 2 \text { stenotic } \\
\text { vessel }\end{array}$ & $\begin{array}{l}\text { With } 3 \text { stenotic } \\
\text { vessel }\end{array}$ & $\begin{array}{l}\text { Total } \\
\text { number }\end{array}$ \\
\hline $\mathrm{CC}$ & $125(46.5)$ & $104(38.6)$ & $40(14.9)$ & 269 \\
\hline $\mathrm{CT}+\mathrm{TT}$ & $37(40.2)$ & 41 (44.6) & $14(15.2)$ & 92 \\
\hline Total & $162(44.9)$ & $145(40.2)$ & 54 (14.9) & 361 \\
\hline
\end{tabular}

Table 6. Logistic regression analysis of association between the MMP9 genotypes and risk of ACS

\begin{tabular}{|c|c|c|c|c|c|c|}
\hline Risk factors & $B$ & $S E$ & Wald $\chi^{2}$ & $P$ & $O R$ & $95 \%$ \\
\hline Hypertension & 1.093 & 0.236 & 9.829 & 0.007 & 2.983 & $1.879-4.734$ \\
\hline Smoking & 0.986 & 0.263 & 14.092 & 0.000 & 2.682 & $1.602-4.488$ \\
\hline DM & 0.591 & 0.117 & 21.876 & 0.000 & 1.915 & $1.523-2.451$ \\
\hline$-1562 \mathrm{~T}$ allele & 0.552 & 0.133 & 5.312 & 0.018 & 1.737 & $1.337-2.257$ \\
\hline $\mathrm{TC}$ & 0.459 & 0.162 & 7.447 & 0.006 & 1.590 & $1.137-2.265$ \\
\hline BMI & 0.257 & 0.064 & 18.344 & 0.000 & 1.313 & $1.356-2.266$ \\
\hline HDL-C & -1.475 & 0.369 & 11.415 & 0.001 & 0.229 & $0.111-0.472$ \\
\hline
\end{tabular}

had an increased risk of ACS $(O R=1.82, P=0.001)$.

\section{Association of MMP-9 $(-1562 \mathrm{C}>\mathrm{T})$ polymorphism with the severity of coronary atherosclerosis}

As shown in Table 5, the percentages of patients with two-vessel and triple-vessel disease were higher in the $\mathrm{C} / \mathrm{T}$ and $\mathrm{T} / \mathrm{T}$ genotype class $(44.6 \%, 15.2 \%)$ than in the $\mathrm{C} / \mathrm{C}$ class $(38.6 \%, 14.9 \%)$. However, the frequencies of CC, $\mathrm{CT}$ and TT genotypes were not significantly different in ACS patients with one, two and three or more diseased vessels $\left(\chi^{2}=1.97, P=0.55\right)$. In the $361 \mathrm{ACS}$ patients with coronary angiographic data, there was no significant association between MMP-9 $(-1562 \mathrm{C}>\mathrm{T})$ polymorphism and the severity of coronary atherosclerosis.

\section{Association of MMP-9 genotypes with ACS risk}

Multifactor logistic regression analysis showed seven independent risk factors for ACS, including hypertension $(O R=2.983,95 \%$ CI $1.879-4.734 ; P<0.01)$, smoking $(O R=2.682,95 \%$ CI 1.602-4.488; $P<0.001)$, diabetes mellitus $(O R=1.915,95 \%$ CI 1.523-2.451; $P<0.001)$, total cholesterol $(O R=1.59,95 \%$ CI 1.137-2.265; $P$ $=0.006)$, body mass index $(O R=1.313,95 \%$ CI 1.356 2.266; $P<0.001)$ and high density lipoprotein cholesterol $(O R=0.229,95 \%$ CI $0.111-0.472 ; P=0.001)$. After adjustment for age, body mass index, smoking, diabetes mellitus, hypertension and hypercholesterolemia, the odds ratio for ACS in patients with $-1562 \mathrm{TT}$ or CT genotype was 1.737 (95\% CI 1.337-2.257, $P=0.018)$ as compared with those with $-1562 \mathrm{CC}$ genotype (Table 6).

\section{DISCUSSION}

This is the first study on the two potentially functional polymorphisms of the MMP-9 gene in relation to ACS susceptibility in the Uygur population of China. The data of this study demonstrated that the $-1562 \mathrm{~T}$ allele of the MMP-9 gene is significantly associated with an increased risk of ACS. However, no association was found between $\mathrm{R} 279 \mathrm{Q}$ polymorphism and ACS risk in this cohort.

MMP-9 possesses proteolytic activity on type IV collagen, a major constitute of the basement membrane that surrounds every vascular smooth muscle cell and underlies the endothelium in the blood vessel wall. ${ }^{[13]}$ The human MMP-9 gene is located on chromosome 20q12.2-13.1, and Zhang et al ${ }^{[14]}$ found a number of single nucleotide polymorphisms (SNPs) in the promoter, coding and untranslated regions. Of these, two polymorphisms, namely promoter $-1562 \mathrm{C}>\mathrm{T}$ 
polymorphism and codon 279 polymorphism (R279Q), are of special significance. Functional studies indicate that the $-1562 \mathrm{C}>\mathrm{T}$ polymorphism has an allelespecific effect on MMP-9 transcription. DNA-protein interaction assays have revealed that the sequence between nucleotide position -1567 and -1559 relative to the transcription start site of the MMP9 gene, which encompasses the -1562 polymorphic site, can interact with a nuclear protein, but its mechanism is still unknown. ${ }^{[15]}$ And codon 279 polymorphism is located in the gelatinase-specific fibronectin type II domain, and can cause an amino acid exchange (arginine [R] to glutamine [Q]) in the catalytic domain, which presumably enhances substrate binding.$^{[16,17]}$ It is possible that the amino acid conversion is associated with this polymorphism, and affect the activity of this enzyme.

Functional studies indicate that the $-1562 \mathrm{C}>\mathrm{T}$ polymorphism has an allele-specific effect on MMP9 transcription. In this study we found that $-1562 \mathrm{CT} /$ TT genotypes were associated with a significantly increased risk of ACS. A genetic epidemiological study ${ }^{[18]}$ indicated that T-1562 allele carriers are predisposed to the development of coronary atherosclerosis, which causes coronary stenosis. Zhang et al ${ }^{[15]}$ reported a functional $1562 \mathrm{C}>\mathrm{T}$ polymorphism in the promoter region of MMP9. Transfection experiments and DNA-protein interaction assays indicated that the $\mathrm{T}$ allele had a higher activity. In addition, Blankenberg et $\mathrm{al}^{[19]}$ reported that plasma MMP9 levels were also higher in $-1562 \mathrm{~T}$ allele carriers than in non-carriers. A study ${ }^{[20]}$ on aortic tissues showed that MMP-9 mRNA levels, MMP-9 protein levels and MMP9 activity were higher in $-1562 \mathrm{~T}$ allele carriers than in non-carriers. MMP-9 knockout studies ${ }^{[21,22]}$ in mice also demonstrated a role of MMP-9 in the development of atherosclerosis. Compared with MMP-9 wild-type mice, MMP-9 deficient mice had fewer and smaller atherosclerotic lesions. ${ }^{[23]}$ Thus, increased vascular smooth muscle migration and macrophage infiltration are likely to explain increased coronary atherosclerosis in carriers of the MMP-9 high expression $-1562 \mathrm{~T}$ allele in humans. These findings suggest that the $-1562 \mathrm{C}>\mathrm{T}$ polymorphism not only affect the MMP-9 promoter activity in vitro experiments, but also influence the MMP-9 transcription in vivo, and this effect is translated into differences in MMP-9 protein level and activity between individuals with different MMP-9 genotypes.

There are many polymorphisms in the MMP-9 gene for CAD. Zhang et al ${ }^{[15]}$ reported that $-1562 \mathrm{~T}$ allele was associated with the severity of coronary atherosclerosis measured by the number of coronary arteries showing a stenosis more than $50 \%$. Mizon-Gerard et al ${ }^{[24]}$ found that patients carrying the MMP-9 gene $-1562 \mathrm{~T}$ allele had a higher cardiac mortality rate than non-carriers. Recently, Zhi et al ${ }^{[25]}$ reported that $-1562 \mathrm{CT} / \mathrm{TT}$ genotypes may contribute to CAD in diabetics and MI in CAD patients in a Chinese population. Fallah et al ${ }^{[26]}$ found that the $-1562 \mathrm{C}>\mathrm{T}$ polymorphism in the MMP9 gene potentially plays a role in the manifestation of coronary atherosclerosis but does not affect the number of diseased vessels. The results of their study were not consistent. Three published studies on 788 Caucasians, 248 Koreans and 2731 German men with angiographically documented CAD failed to confirm an association with the T allele. ${ }^{[27-29]}$

Genetic polymorphisms may vary in different ethnic groups. In our study population, the genotype frequencies of $-1562 \mathrm{C}>\mathrm{T}$ polymorphism for $\mathrm{CC}, \mathrm{CT}$ and TT were $84.2 \%, 14.7 \%$ and $1.1 \%$ respectively in the control subjects, and $74.5 \%, 22.4 \%$ and $3.1 \%$ in the ACS patients respectively. The genotype frequencies for $\mathrm{CT}+\mathrm{TT}$ genotypes and the $-1562 \mathrm{~T}$ allele were significantly higher in the ACS group than in the control group (25.5\% vs. $15.8 \%$ and $14.3 \%$ vs. $8.5 \%$, $P=0.001$ and $P<0.001$, respectively). After adjustment for age, gender, smoking, hypertension, diabetes mellitus and hypercholesterolemia, the $\mathrm{T}$ allele carriers had an approximately 1.74-fold higher risk of developing ACS than those with the CC homozygote. It has also been found that MMP-9 is highly expressed in the shoulder regions of advanced atherosclerotic lesions and therefore it is suggested that this potent matrix-degrading enzyme also contributes to plaque instability. ${ }^{[30-32]}$ Similar to the findings of Fallah et al, we did not find that $-1562 \mathrm{C}>\mathrm{T}$ polymorphism has any significant effect on the number of diseased vessels.

The 279Q allele was found to be associated with increased MMP-9 levels and the combined end point of cardiovascular death and non-fatal myocardial infarction. ${ }^{[19]}$ Whereas in the other studies, ${ }^{[18,27,33]} \mathrm{R} 279 \mathrm{Q}$ polymorphism was not found to be associated with risk of CAD and stable angina. As well, we did not find any significant differences in both the genotype and allele distribution between the ACS group and the control group in this population.

In conclusion, this study suggests that MMP-9 $-1562 \mathrm{C}>\mathrm{T}$ polymorphism could be associated with the susceptibility to ACS in the Uygur population of China, and the $-1562 \mathrm{~T}$ allele carriers might be at high risk of the development of ACS. The results are consistent with the notion that MMP-9 plays an important role in the 
development of atherosclerotic lesion and arterial plaque rupture ${ }^{[9,10]}$ However, this mutation apparently is not related to the severity of coronary arterial stenosis.

Funding: The study was supported by a grant from the Great Technology Special Program Foundation of Xinjiang, China (200733146-3).

Ethical approval: The study was approved by the Ethics Committee of the First Hospital Affiliated to Xinjiang Medical University.

Conflicts of interest: No benefits in any form have been received or will be received from a commercial party related directly or indirectly to the subjects of this article.

Contributors: Wang L proposed and wrote the first draft. All authors contributed to the design and interpretation of the study and to further drafts. Ma YT is the guarantor.

\section{REFERENCES}

1 Liu Y, Liao YH, Cheng X. Immunologic mechanisms and treatment of acute coronary syndromes. Chin Med J (Engl) 2006; 119: 2108-2113.

2 Libby P. Molecular bases of the acute coronary syndromes. Circulation 1995; 91: 2844-2850.

3 Davies MJ. Stability and instability: two faces of coronary atherosclerosis. The Paul Dudley White Lecture 1995. Circulation 1996; 94: 2013-2020.

4 Anderson KM, Wilson PW, Odell PM, Kannel WB. An updated coronary risk profile. A statement for health professionals. Circulation 1991; 83: 356-362.

5 Kannel WB. Lipids, diabetes, and coronary heart disease: insights from the Framingham Study. Am Heart J 1985; 110: 1100-1107.

6 Yano K, Reed DM, McGee DL. Ten-year incidence of coronary heart disease in the Honolulu Heart Program. Relationship to biologic and lifestyle characteristics. Am J Epidemiol 1984; 119: 653-666.

7 Visse R, Nagase H. Matrix metalloproteinases and tissue inhibitors of metalloproteinases: structure, function, and biochemistry. Circ Res 2003; 92: 827-839.

8 Henney AM, Ye S, Zhang B, Jormsjö S, Whatling C, Eriksson $\mathrm{P}$, et al. Genetic diversity in the matrix metalloproteinase family. Effects on function and disease progression. Ann N Y Acad Sci 2000; 902: 27-38.

9 Galis ZS, Khatri JJ. Matrix metalloproteinases in vascular remodeling and atherogenesis: the good, the bad, and the ugly. Circ Res 2002; 90: 251-262.

10 Loftus IM, Naylor AR, Goodall S, Crowther M, Jones L, Bell PR, et al. Increased matrix metalloproteinase- 9 activity in unstable carotid plaques: A potential role in acute plaque disruption. Stroke 2000; 31: 40-47.

11 Kai H, Ikeda H, Yasukawa H, Kai M, Seki Y, Kuwahara F, et al. Peripheral blood levels of matrix metalloproteases-2 and -9 are elevated in patients with acute coronary syndromes. J Am Coll
Cardiol 1998; 32: 368-372.

12 Inokubo Y, Hanada H, Ishizaka H, Fukushi T, Kamada T, Okumura K. Plasma levels of matrix metalloproteinase-9 and tissue inhibitor of metalloproteinase-1 are increased in the coronary circulation in patients with acute coronary syndrome. Am Heart J 2001; 141: 211-217.

13 Newby AC. Dual role of matrix metalloproteinases (matrixins) in intimal thickening and atherosclerotic plaque rupture. Physiol Rev 2005; 85: 1-31.

14 Zhang B, Henney A, Eriksson P, Hamsten A, Watkins H, Ye S. Genetic variation at the matrix metalloproteinase-9 locus on chromosome 20q12.2-13.1. Hum Genet 1999; 105: 418-423.

15 Zhang B, Ye S, Herrmann SM, Eriksson P, de Maat M, Evans A, Arveiler D, et al. Functional polymorphism in the regulatory region of gelatinase $\mathrm{B}$ gene in relation to severity of coronary atherosclerosis. Circulation 1999; 99: 1788-1794.

16 Allan JA, Docherty AJ, Barker PJ, Huskisson NS, Reynolds JJ, Murphy G. Binding of gelatinases A and B to type-I collagen and other matrix components. Biochem J 1998; 309: 299-306.

17 O'Farrell TJ, Pourmotabbed T. Identification of structural elements important for matrix metalloproteinase type $\mathrm{V}$ collagenolytic activity as revealed by chimeric enzymes. Role of fibronectin-like domain and active site of gelatinase B. J Biol Chem 2000; 275: 27964-27967.

18 Morgan AR, Zhang B, Tapper W, et al. Haplotypic analysis of the MMP-9 gene in relation to coronary artery disease. J Mol Med 2003; 81: 321-326.

19 Blankenberg S, Rupprecht HJ, Poirier O, Collins A, Ye S. Plasma concentrations and genetic variation of matrix metalloproteinase 9 and prognosis of patients with cardiovascular disease. Circulation 2003; 107: 1579-1585.

20 Medley TL, Cole TJ, Dart AM, Gatzka CD, Kingwell BA. Matrix metalloproteinase-9 genotype influences large artery stiffness through effects on aortic gene and protein expression. Arterioscler Thromb Vasc Biol 2004; 24: 1479-1484.

21 Galis ZS, Johnson C, Godin D, Magid R, Shipley JM, Senior $\mathrm{RM}$, et al. Targeted disruption of the matrix metalloproteinase- 9 gene impairs smooth muscle cell migration arterial remodeling and geometrical. Circ Res 2002; 91: 852-859.

22 Johnson C, Galis ZS. Matrix metalloproteinase-2 and-9 differentially regulate smooth muscle cell migration and cellmediated collagen organization. Arterioscler Thromb Vasc Biol 2004; 249: 54-60.

23 Luttun A, Lutgens E, Manderveld A, Maris K, Collen D, Carmeliet $\mathrm{P}$, et al. Loss of matrix metalloproteinase-9 or matrix metalloproteinase-12 protects apolipoprotein E-deficient mice against atherosclerotic media destruction but differentially affects plaque growth. Circulation 2004, 109: 1408 -1414.

24 Mizon-Gerard F, de Groote P, Lamblin N, Hermant X, Dallongeville J, Amouyel P, et al. Prognostic impact of matrix metalloproteinase gene polymorphisms in patients with heart failure according to the aetiology of left ventricular systolic dysfunction. Eur Heart J 2004; 25: 688-693.

25 Zhi H, Wang H, Ren L, Shi Z, Peng H, Cui L, et al. Functional polymorphisms of matrix metallopeptidase-9 and risk of coronary artery disease in a Chinese population. Mol Biol Rep 
2010; 37: 13-20.

26 Fallah S, Seifi M, Ghasemi A, Firoozrai M, Samadikuchaksaraei A. Matrix metalloproteinase-9 and paraoxonase 1 Q/R192 gene polymorphisms and the risk of coronary artery stenosis in Iranian subjects. J Clin lab Anal 2010; 24: 305-310.

27 Kim JS, Park HY, Kwon JH, Im EK, Choi DH, Jang YS, et al. The roles of stromelysin-1 and the gelatinase B gene polymorphism in stable angina. Yonsei Med J 2002; 43: 473-481.

28 Wang J, Warzecha D, Wilcken D, Wang XL. Polymorphism in the gelatinase B gene and the severity of coronary arterial stenosis. Clin Sci (Lond) 2001; 101: 87-92.

29 Haberbosch W, Gardemann A. Gelatinase B C $(-1562) \mathrm{T}$ polymorphism in relation to ischaemic heart disease. Scand $\mathrm{J}$ Clin Lab Invest 2005; 65: 513-522.

30 Galis ZS, Sukhova GK, Lark MW, Libby P. Increased expression of matrix metalloproteinases and matrix degrading activity in vulnerable regions of human atherosclerotic plaques. J Clin
Invest 1994; 94: 2493-2503.

31 Brown DL, Hibbs MS, Kearney M, Loushin C, Isner JM. Identification of 92-kD gelatinase in human coronary atherosclerotic lesions: Association of active enzyme synthesis with unstable angina. Circulation 1995; 91: 2125-2131.

32 Zaltsman AB, Newby AC. Increased secretion of gelatinases A and $\mathrm{B}$ from the aortas of cholesterol fed rabbits: relationship to lesion severity. Atherosclerosis 1997; 130: 61-70.

33 Lamblin N, Bauters C, Hermant X, Lablanche JM, Helbecque N, Amouyel P. Polymorphisms in the promoter regions of MMP2, MMP-3, MMP-9 and MMP-12 genes as determinants of aneurysmal coronary artery disease. J Am Coll Cardiol 2002; 40: 43-48.

Received November 19, 2010 Accepted after revision March 17, 2011 